\title{
Neonatal ibuprofen exposure and bronchopulmonary dysplasia in extremely premature infants
}

\author{
Xueyu Chen $\mathbb{1}^{1} \cdot$ Xiaomei Qiu ${ }^{1}$ Panpan Sun $\mathbb{1}^{1} \cdot$ Yanqing $\operatorname{Lin}^{1} \cdot$ Zhifeng Huang ${ }^{1} \cdot$ Chuanzhong Yang $\mathbb{C}^{1} \cdot$ \\ Frans J. Walther ${ }^{2,3}$
}

Received: 11 February 2019 / Revised: 8 June 2019 / Accepted: 14 June 2019 / Published online: 7 August 2019

(c) The Author(s) 2019. This article is published with open access

\begin{abstract}
Objective To evaluate the association of ibuprofen exposure with the risk of bronchopulmonary dysplasia (BPD) in extremely premature infants.

Study design This was a retrospective study of all extremely premature infants admitted to a tertiary unit from 2016 to 2018. Results A total of 203 extremely premature infants were included in this study. The rate of BPD was significantly higher in infants with early exposure to ibuprofen $(42.5 \%)$ compared to infants with no exposure $(21.6 \%, P=0.001)$. After adjusting for covariates, the risk of BPD was associated independently with ibuprofen exposure (odds ratios (OR) 2.296, 95\% confidence interval $(\mathrm{CI}): 1.166-4.522, p=0.016)$. Further analysis showed a trend towards higher risk of BPD in infants with successful patent ductus arteriosus (PDA) closure after ibuprofen treatment (32.3\%) compared to non-treated infants $(20.2 \%, p=0.162)$.
\end{abstract}

Conclusion Our findings suggest that ibuprofen exposure may contribute to the occurrence of BPD in extremely preterm infants.

\section{Introduction}

Extremely premature infants (gestational age $\leq 28$ weeks) are at high risk of bronchopulmonary dysplasia (BPD) [1]. The prevalence of BPD in extremely premature infants remains stable at around 40\% [2,3] despite great advances in prenatal care in recent years. BPD is characterized by arrested alveolar and vascular development [4]. As a result, survivors of BPD suffer from short and long-term complications from neonatal infection to adolescent asthma and

Chuanzhong Yang

yangczgd@163.com

$\square$ Frans J. Walther

fjwalther@ucla.edu

1 Department of Neonatology, Affiliated Shenzhen Maternity \& Child Healthcare Hospital, Southern Medical University, Shenzhen, China

2 Department of Pediatrics, David Geffen School of Medicine, University of California Los Angeles, Los Angeles, CA, USA

3 Los Angeles Biomedical Research Institute at Harbor-UCLA Medical Center, Torrance, CA, USA chronic obstructive pulmonary disease (COPD) in adult life [5].

Many efforts have been devoted to identifying factors that deteriorate lung development after extremely preterm birth [6]. Ibuprofen is one of the nonsteroidal anti-inflammatory drugs (NSAIDs) and is extensively used for the treatment of patent ductus arteriosus (PDA) [7, 8]. Recently, the adversity of early exposure to ibuprofen in newborns has drawn much attention [8-10], among which pulmonary arterial hypertension (PAH) is a significant problem [11-13]. Notably, in vitro and in vivo experiments corroborate that ibuprofen inhibits angiogenesis $[14,15]$. Blunted angiogenesis is exactly the underlying mechanism of both neonatal PAH and BPD [16].

The association between early exposure to ibuprofen and BPD remains controversial. Several studies reported that ibuprofen was not associated with the development BPD (as exploratory outcome) $[17,18]$. Ohlsson et al. found no difference in the prevalence of BPD in infants with or without ibuprofen treatment [18]. Mitra et al. found a reduced risk of BPD after ibuprofen treatment compared to placebo [17]. However, a large proportion of the controls in those studies actually received treatment for PDA [19], leading to concerns about the accuracy of the conclusion in those studies. Therefore, this study aims to investigate the association of early 
ibuprofen exposure with BPD in a cohort of extremely premature infants. This study also compares the prevalence of BPD in subgroups stratified by PDA status.

\section{Methods}

This retrospective study was conducted at the neonatal intensive care unit (NICU) of Shenzhen Maternal \& Child Healthcare Hospital between January 2016 and July 2018. All neonates born before 28 weeks' gestation at our center were eligible for this study. During the study period, oral ibuprofen (Melian, Shanghai Johnson \& Johnson Pharmaceuticals Co., Ltd, Shanghai, China) was used only for hemodynamic significant PDA. A course of treatment was defined as an initial dose of $10 \mathrm{mg} / \mathrm{kg}$ body weight on the first day followed by $5 \mathrm{mg} / \mathrm{kg}$ on the second and third day. This study was approved by the Shenzhen Maternity \& Child Healthcare Hospital Institutional Ethical Committee and the requirement for informed consent was waived by the committee.

Extreme prematurity was defined as delivery at a gestational age $\leq 28$ weeks. An echocardiogram was routinely performed within $72 \mathrm{~h}$ after birth. A hemodynamically significant PDA (hsPDA) was diagnosed by the presence of a ductus with a diameter $>1.5 \mathrm{~mm}$, left atrial inner diameter/aortic root $(\mathrm{LA} / \mathrm{AO}) \geq 1.4$, combined left to right shunt [20]. Infants with a hemodynamically significant PDA received at least one course of oral ibuprofen in absence of contraindications such as a low platelet count $(<50,000$ per $\mathrm{mL})$, oliguria, bloody vomit, necrotizing enterocolitis (NEC) and renal deficiency. Another echocardiogram was performed within $48 \mathrm{~h}$ after each treatment course. BPD was diagnosed when supplemental oxygen was required at 36 weeks postmenstrual age (PMA) or discharge [21].

Data were retrieved from the electronic medical record, including maternal complications such as gestational hypertension and gestational diabetes mellitus (GDM), maternal infection, antenatal steroid treatment, delivery methods, gestational age (GA), birth weight (BW), Apgar score, gender, surfactant treatment, ventilation mode, PDA and information about ibuprofen treatment.

\section{Statistics}

The sample size calculation was based on the prevalence of BPD in our unit. The rate of BPD in ibuprofen treated infants and not treated ones were around $40 \%$ vs $20 \%$. At $80 \%$ power and $\alpha=0.05,80$ infants in each group would be sufficient to detect a significant difference (PASS, Version 11, NCSS, LLC, Utah). The Shapiro-Wilk test was used to evaluate the normality of continuous variables and the independent $t$-test (two sides) and the Mann-Whitney $U$ test to analyze continuous variables according to the normality. Chi-square or Fisher's exact tests were used to compare categorical data, as appropriate. Potential risk factors for BPD were first assessed in a univariable regression model (binary regression). Those factors significantly associated with BPD were then inserted into a multivariable logistic regression model (Forward) to evaluate their independence in relation to BPD. Odds ratios (OR) and 95\% confidence interval $(\mathrm{CI})$ were calculated using univariable and multivariate regression analysis. The analysis was performed using SPSS statistical software version 24.0 (IBM Corporation, NY).

\section{Results}

A total of 276 extremely premature infants were admitted to our NICU during the study period. In total 18 infants were excluded because of referral from other hospitals and incomplete data. A total of 55 infants were also excluded
Fig. 1 Flowchart of case selection and analyses
276 extremely premature infants admitted to NICU

18 infants exluded due to referral from other hospitals

258 extremely premature infants

55 infants excluded due to intensive care withdrawn before 28 days after birth

203 extremely premature infants

62 infants developed bronchopulmonary dysplasia (supplemental oxygen needed at 36 PMA or discharge). 
due to withdrawal from intensive care before 28 days after birth by parents' choice. The remaining 203 extremely premature infants were included in this study (Fig. 1). BPD was diagnosed in $62(30.5 \%)$ infants. The clinical characteristics by ibuprofen exposure are summarized in Table 1.

The univariable analysis showed that the occurrence of BPD was associated with gestational age, birth weight, intubation, 1- and 5-min Apgar score, surfactant

Table 1 Clinical characteristics by ibuprofen exposure

\begin{tabular}{|c|c|c|c|}
\hline Variable & $\begin{array}{l}\text { no ibuprofen } \\
(n=116)\end{array}$ & $\begin{array}{l}\text { ibuprofen } \\
(n=87)\end{array}$ & $\mathrm{P}$ value \\
\hline GDM & $13(11.2 \%)$ & $10(11.5 \%)$ & 0.949 \\
\hline $\begin{array}{l}\text { Gestational } \\
\text { hypertension }\end{array}$ & $3(2.6 \%)$ & $4(4.6 \%)$ & 0.465 \\
\hline Maternal infection & $16(13.8 \%)$ & $15(17.2 \%)$ & 0.499 \\
\hline Fetal distress & $4(3.4 \%)$ & $5(5.7 \%)$ & 0.502 \\
\hline $\begin{array}{l}\text { Antenatal steroid } \\
\text { treatment }\end{array}$ & $86(74.1 \%)$ & $70(80.5 \%)$ & 0.224 \\
\hline $\begin{array}{l}\text { Cesarean section } \\
\text { delivery }\end{array}$ & $26(22.4 \%)$ & $23(26.4 \%)$ & 0.507 \\
\hline $\begin{array}{l}\text { Gestational age at } \\
\text { birth (wk) }\end{array}$ & $27.0(26.0-27.3)$ & $26.2(24.6-27.2)$ & 0.012 \\
\hline Birth weight (gr) & $943 \pm 189$ & $866 \pm 204$ & 0.006 \\
\hline Male & $68(58.6 \%)$ & $54(62.1 \%)$ & 0.620 \\
\hline Intubation & $48(41.4 \%)$ & $53(60.9 \%)$ & 0.006 \\
\hline Apgar score at $1 \mathrm{~min}$ & $7(5-9)$ & $5.5(5-8)$ & 0.035 \\
\hline Apgar score at $5 \mathrm{~min}$ & $10(9-10)$ & $10(9-10)$ & 0.165 \\
\hline Surfactant treatment & $89(76.7 \%)$ & $82(94.2 \%)$ & 0.001 \\
\hline BPD & $25(21.6 \%)$ & $37(42.5 \%)$ & 0.001 \\
\hline IVH & $33(28.4 \%)$ & $31(35.6 \%)$ & 0.276 \\
\hline $\begin{array}{l}\text { Gastrointestinal } \\
\text { perforation }\end{array}$ & $11(9.5 \%)$ & $13(14.9 \%)$ & 0.230 \\
\hline Intervened ROP & $16(13.8 \%)$ & $25(28.7 \%)$ & 0.008 \\
\hline
\end{tabular}

Data were displayed as mean $\pm \mathrm{SD}$, median (interquartile range) or number (percentage). GDM gestational diabetes mellitus, $B P D$ bronchopulmonary dysplasia (oxygen needed at PMA 36 weeks), $I V H$ intraventricular Hemorrhage, $R O P$ retinopathy of prematurity, intervened ROP was defined as ROP requiring either laser therapy or medication injection treatment, hsPDA and ibuprofen exposure. These risk factors were subsequently entered into the multivariable regression model (Table 2). We found that the occurrence of BPD was independently associated with gestational age (OR 0.498, 95\% CI: 0.374-0.662, $P<0.000$ ) and ibuprofen exposure (OR 2.296, 95\% CI: 1.166-4.522, $p=0.016)$.

In our cohort, 42.8\% (87/203) infants were given at least one course of ibuprofen for the treatment of PDA, yielding a successful closure rate of $35.6 \%$ (31/87) within $48 \mathrm{~h}$ after completion of the treatment course. The median age for the first dose of ibuprofen was $6.5(4,9.25)$ day, with median feeding volume $1(0.5,2.5) \mathrm{ml}$ per feeding. $23.0 \%$ (20/87) infants receiving ibuprofen treatment suffered from feeding intolerance or gastric complications within $72 \mathrm{~h}$ after the first dose.

To eliminate the confounding of PDA, we further analyzed the association of ibuprofen with the risk of BPD by stratifying ductal status. We found that among infants with a closed ductus (either by itself or by ibuprofen treatment), the frequency of BPD in infants with early ibuprofen exposure $(32.3 \%)$ was not significantly higher than infants receiving no ibuprofen $(20.2 \%$; OR 1.883 , 95\% CI $0.776-4.570, p=0.162$; Fig. 2). A similar finding of the prevalence of BPD was found in infants with an open ductus (either treated or not treated with ibuprofen), $49.0 \%$ and $42.9 \%$, respectively, (OR $0.962,95 \%$ CI $0.217-4.269$, $p=0.959$; Fig. 2). Furthermore, PDA increased (not significantly) the risk of BPD in infants not receiving ibuprofen $(42.9 \%$ and $20.2 \%)$ and receiving ibuprofen $(49.0 \%$ and $32.3 \%$, Fig. 2).

The clinical characteristics of infants during ibuprofen treatment were described in Table 3. The median age, feeding volume and rate of a single course of treatment were similar between the infants developing BPD and those not (7th vs 6th day, $p=0.670 ; 2$ vs $1 \mathrm{ml} /$ feeding, $p=0.995$; $62.2 \%$ vs $70 \%, p=0.265$, respectively). Infants who
Table 2 Univariate and multivariate logistic regression analysis of selected variables associated with BPD

\begin{tabular}{llrrrr}
\hline Variables & Univariate & & \multicolumn{2}{l}{ Multivariate } \\
\cline { 2 - 3 } \cline { 5 - 6 } & RR $(95 \%$ C.I. $)$ & $P$ value & & RR $(95 \%$ C.I. $)$ & $P$ value \\
\hline Ibuprofen exposure & $2.694(1.458,4.975)$ & 0.001 & & $2.296(1.166,4.522)$ & 0.016 \\
Gestational age & $0.480(0.364,0.633)$ & $<0.001$ & & $0.498(0.374,0.662)$ & $<0.001$ \\
1 min Apgar Score & $0.791(0.684,0.915)$ & 0.002 & - & 0.118 \\
5 min Apgar Score & $0.747(0.565,0.986)$ & 0.009 & & - & 0.971 \\
Birth weight & $0.996(0.994,0.998)$ & $<0.001$ & & - & 0.236 \\
Intubation & $2.385(1.286,4.423)$ & 0.005 & & - & 0.686 \\
Surfactant & $4.500(1.309,15.464)$ & 0.010 & & - & 0.356 \\
HsPDA & $2.929(1.574,5.452)$ & 0.001 & & - & 0.857 \\
\hline
\end{tabular}

BPD was diagnosed when supplemental oxygen required at 36 weeks PMA. HsPDA (hemodynamically significant PDA) was defined as the presence of a ductus with a diameter $>1.5 \mathrm{~mm}, \mathrm{LA} / \mathrm{AO}$ (left atrial inner diameter/aortic root) $\geq 1.4$, combined left to right shunt 
developed BPD, compared to infants who did not, show no significant differences in the rate of feeding intolerance ( $18.9 \%$ vs $26 \%, p=0.439)$ or the rate for PDA surgical ligation $(18.9 \%$ vs $8 \%, p=0.140)$.

\section{Discussion}

This study showed that BPD is approximately 2-fold more likely to occur in infants exposed to ibuprofen during the first days of life. This suggests that early ibuprofen exposure in neonatal may contribute to the occurrence of BPD in extremely premature infants.

The association of ibuprofen with the development of BPD has been a great interest of neonatologists. In two systematic and meta-analysis, Ohlsson et al. and Mitra et al. reported no effect of ibuprofen on BPD development [17, 18], which is inconsistent with the findings in this study and may be due to differences in the control group (infants with open ductus in their studies), study population (GA $<37$ weeks in their studies) and the diagnostic standard of BPD. In addition, up to $85 \%$ (an average of 50\%) of the control infants in previous RCTs actually received treatments of PDA in the later study

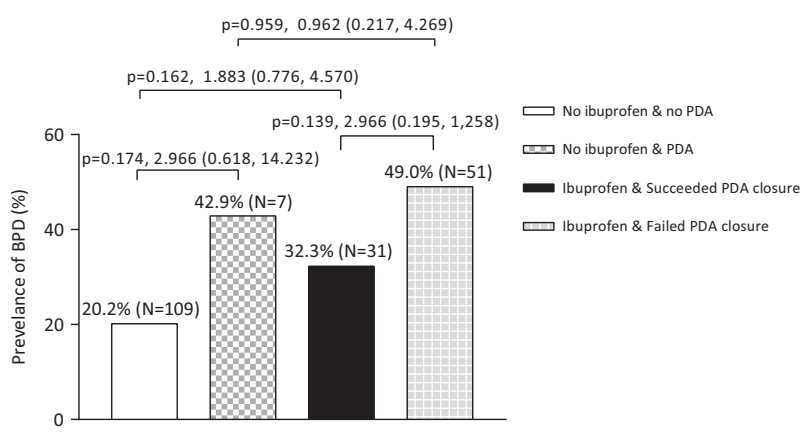

Fig. 2 Analysis of ibuprofen exposure and the risk of BPD in subgroups with variate ductal status. Comparisons were performed between groups with a bridge connecting them. Prevalence of BPD, sample size, $p$-value, OR and $95 \%$ C.I. was indicated on the bars and bridges period. Therefore the conclusion of the systematic and metaanalysis can only be made between the early- and late-treated PDA instead of treated and non-treated PDA [19]. Fortunately, the awareness of this limitation in previous RCTs is well recognized and new trials on PDA management have been initiated, such as Baby-Oscar (https://www.npeu.ox.ac.uk/ba by-oscar), PDA trial (https://clinicaltrials.gov/ct2/show/ NCT03456336) and Benedictus (https://Neonatologynetwork. eu/studies/beneductus). The completion of these trials would provide solid evidence of an association between ibuprofen exposure and BPD.

It's unclear why early exposure to ibuprofen is associated with an increased risk of BPD. BPD is characterized as arrested alveolar and vascular development [22]. Ex vivo experiments substantiate that ibuprofen inhibits angiogenesis by disturbing the tube formation ability of human umbilical vein endothelial cell (HUVEC) [14]. In newborn rats, ibuprofen significantly diminishes neovascularization [15]. Clinical studies demonstrate a higher frequency of PAH after ibuprofen treatment in very low birth weight infants $(<1500 \mathrm{~g})$ [23]. Collectively, the anti-angiogenetic effect of ibuprofen might be the underlying mechanism of its effect on BPD, especially in extremely premature infants who are more vulnerable to blocked angiogenesis. However, multiple courses of ibuprofen exposure did not significantly increase the risk of BPD (this study), which may be owing to the small sample size.

However, further analysis of the association between ibuprofen and BPD among subgroups did not confirm the findings in the whole cohort. In infants with a closed ductus, the prevalence of BPD in infants without ibuprofen treatment $(N=109,20.2 \%)$ is not significantly lower than in infants exposed to ibuprofen $(N=31,32.3 \%)$. A similar result was found in infants with an open ductus (42.9\% vs $49.0 \%)$. The discrepancy of these findings may be attributed to the relatively small sample size of the subgroups. Notably, the close rate of ibuprofen on PDA in the current study (35.6\%) is lower compared with other studies, where the closure is about $56.7 \%-78.8 \%[17,24,25]$. This difference in closure rate of
Table 3 Variates about ibuprofen treatment and their association with BPD

\begin{tabular}{lcccc}
\hline & BPD $(n=37)$ & Non-BPD $(n=50)$ & OR $(95 \% \mathrm{CI})$ & $P$ value \\
\hline $\begin{array}{l}\text { Age of the first dose of } \\
\text { ibuprofen (Day) }\end{array}$ & $7(3.5,10.5)$ & $6(4,9)$ & $0.982(0.901,1.069)$ & 0.670 \\
$\begin{array}{l}\text { Feeding volume at the first dose } \\
\text { (ml/feeding) }\end{array}$ & $2(1,3)$ & $1(0.5,2.375)$ & $0.995(0.907,1.091)$ & 0.995 \\
$\begin{array}{l}\text { Feeding intolerance } \\
\text { Single course of ibuprofen }\end{array}$ & $7(18.9 \%)$ & $13(26 \%)$ & $0.664(0.235,1.874)$ & 0.439 \\
$\begin{array}{l}\text { Multiple course of ibuprofen } \\
\text { PDA surgical ligation }\end{array}$ & $14(62.2 \%)$ & $35(70 \%)$ & $1.528(0.725,3.219)$ & 0.265 \\
\hline
\end{tabular}

Feeding intolerance, including gastric residuals, abdominal distension, vomiting and gastric bleeding occurred within $72 \mathrm{~h}$ after the first dose of ibuprofen 
PDA by ibuprofen may be explained by a different route of administrating ibuprofen, study population and various starting age in those studies. Both younger gestational age and later treatment contributed to the failure of pharmaceutical closure of PDA. In the study from Bagnoli et al., 50\% of infants with birth weight $\leq 750 \mathrm{~g}$ required surgical ligation [24].

The main limitation of our study, besides the retrospective nature, is the relatively limited sample size, especially in the subgroups. Besides, infants with non-treated PDA are usually the ones with abdominal complications, which may be associated with the occurrence of respiratory disorders in infants themselves. Therefore, our conclusion should be interpreted with care when extrapolating to the general population.

In summary, early exposure of ibuprofen may be associated with an increased risk of BPD in extremely premature infants. Larger cohorts are required to investigate the possible negative effects of ibuprofen exposure on the developing premature lung.

Acknowledgements Supported by Shenzhen Science and Technology Innovation Committee (JCYJ20160429102107498 to CY and JCYJ20180306173125699 to XC); Shenzhen Medical Sanming Project (SZSM201612045); Shenzhen Health and Family Planning Commission (201606028 to YL) and institutional project (FYA2018018 to CY). The funders were not involved in the study design, data collection, analysis, interpretation, or manuscript preparation.

\section{Compliance with ethical standards}

Conflict of interest The authors declare that they have no conflict of interest.

Publisher's note: Springer Nature remains neutral with regard to jurisdictional claims in published maps and institutional affiliations.

Open Access This article is licensed under a Creative Commons Attribution 4.0 International License, which permits use, sharing, adaptation, distribution and reproduction in any medium or format, as long as you give appropriate credit to the original author(s) and the source, provide a link to the Creative Commons license, and indicate if changes were made. The images or other third party material in this article are included in the article's Creative Commons license, unless indicated otherwise in a credit line to the material. If material is not included in the article's Creative Commons license and your intended use is not permitted by statutory regulation or exceeds the permitted use, you will need to obtain permission directly from the copyright holder. To view a copy of this license, visit http://creativecommons. org/licenses/by/4.0/.

\section{References}

1. Blencowe H, Cousens S, Chou D, Oestergaard M, Say L, Moller $\mathrm{AB}$, et al. Born too soon: the global epidemiology of 15 million preterm births. Reprod health. 2013;10(Suppl 1):S2.

2. Bassler D, Shinwell ES, Hallman M, Jarreau PH, Plavka R, Carnielli $\mathrm{V}$, et al. Long-term effects of inhaled budesonide for bronchopulmonary dysplasia. New Engl J Med. 2018;378:148-57.
3. Hasan SU, Potenziano J, Konduri GG, Perez JA, Van Meurs KP, Walker MW, et al. Effect of inhaled nitric oxide on survival without bronchopulmonary dysplasia in preterm infants: a randomized clinical trial. JAMA Pediatr. 2017;171:1081-9.

4. Morty RE. Recent advances in the pathogenesis of BPD. Semin Perinatol. 2018;42:404-12.

5. El Mazloum D, Moschino L, Bozzetto S, Baraldi E. Chronic lung disease of prematurity: long-term respiratory outcome. Neonatology. 2014;105:352-6.

6. Durrmeyer X, Kayem G, Sinico M, Dassieu G, Danan C, Decobert $\mathrm{F}$. Perinatal risk factors for bronchopulmonary dysplasia in extremely low gestational age infants: a pregnancy disorder-based approach. J Pediatr. 2012;160:578-583.e572.

7. Benitz WE. Patent Ductus Arteriosus in Preterm Infants. Pediatrics 2016;137:e20153730.

8. Moriarty C, Carroll W. Ibuprofen in paediatrics: pharmacology, prescribing and controversies. Arch Dis Child Educ Pract Ed. 2016;101:327-30.

9. Sarici SU, Dabak O, Erdinc K, Okutan V, Lenk MK. An unreported complication of intravenously administered ibuprofen: gastrointestinal bleeding. Eur Rev Med Pharmacol Sci. 2012;16:325-7.

10. Sordillo JE, Scirica CV, Rifas-Shiman SL, Gillman MW, Bunyavanich S, Camargo CA Jr., et al. Prenatal and infant exposure to acetaminophen and ibuprofen and the risk for wheeze and asthma in children. J allergy Clin Immunol. 2015;135:441-8.

11. Amendolia B, Lynn M, Bhat V, Ritz SB, Aghai ZH. Severe pulmonary hypertension with therapeutic L-lysine ibuprofen in 2 preterm neonates. Pediatrics. 2012;129:e1360-3.

12. Gournay V, Savagner C, Thiriez G, Kuster A, Roze JC. Pulmonary hypertension after ibuprofen prophylaxis in very preterm infants. Lancet. 2002;359:1486-8.

13. Bravo MC, Cordeiro M, Deiros L, Perez-Rodriguez J. Lethal pulmonary hypertension associated with ibuprofen treatment in a very low birth weight infant. J Paediatr Child Health. 2014;50:85-6.

14. Akrami H, Aminzadeh S, Fallahi H. Inhibitory effect of ibuprofen on tumor survival and angiogenesis in gastric cancer cell. Tumour Biol: J Int Soc Oncodev Biol Med. 2015;36:3237-43.

15. Beharry KD, Modanlou HD, Hasan J, Gharraee Z, Abad-Santos P, Sills JH, et al. Comparative effects of early postnatal ibuprofen and indomethacin on VEGF, IGF-I, and GH during rat ocular development. Invest Ophthalmol Vis Sci. 2006;47:3036-43.

16. Mourani PM, Abman SH. Pulmonary hypertension and vascular abnormalities in bronchopulmonary dysplasia. Clin Perinatol. 2015;42:839-55.

17. Mitra S, Florez ID, Tamayo ME, Mbuagbaw L, Vanniyasingam T, Veroniki AA, et al. Association of placebo, indomethacin, ibuprofen, and acetaminophen with closure of hemodynamically significant patent ductus arteriosus in preterm infants: a systematic review and meta-analysis. J Am Med Assoc. 2018;319:1221-38.

18. Ohlsson A, Walia R, Shah SS. Ibuprofen for the treatment of patent ductus arteriosus in preterm or low birth weight (or both) infants. Cochrane database Syst Rev. 2018;9:Cd003481.

19. Hundscheid T, Onland W, van Overmeire B, Dijk P, van Kaam A, Dijkman KP, et al. Early treatment versus expectative management of patent ductus arteriosus in preterm infants: a multicentre, randomised, non-inferiority trial in Europe (BeNeDuctus trial). BMC Pediatr. 2018;18:262.

20. Jain A, Shah PSDiagnosis. Evaluation, and management of patent ductus arteriosus in preterm neonates. JAMA Pediatr. 2015; 169:863-72.

21. Higgins RD, Jobe AH, Koso-Thomas M, Bancalari E, Viscardi RM, Hartert TV, et al. Bronchopulmonary dysplasia: executive summary of a workshop. J Pediatr. 2018;197:300-8.

22. Voynow JA. "New" bronchopulmonary dysplasia and chronic lung disease. Paediatr Respir Rev. 2017;24:17-8. 
23. Kim SY, Shin SH, Kim HS, Jung YH, Kim EK, Choi JH. Pulmonary arterial hypertension after ibuprofen treatment for patent ductus arteriosus in very low birth weight infants. J Pediatr. 2016;179:49-53.e41.

24. Bagnoli F, Rossetti A, Messina G, Mori A, Casucci M, Tomasini B. Treatment of patent ductus arteriosus (PDA) using ibuprofen: renal side-effects in VLBW and ELBW newborns. J Matern-fetal Neonatal Med. 2013;26:423-9.

25. Dang D, Wang D, Zhang C, Zhou W, Zhou Q, Wu H. Comparison of oral paracetamol versus ibuprofen in premature infants with patent ductus arteriosus: a randomized controlled trial. PLoS ONE. 2013;8:e77888. 